\title{
Commentary: Totally endoscopic bypass grafting: Hunting for a Norwegian mushroom
}

\author{
Gianluca Torregrossa, MD, and John D. Puskas, MD, MSc, FACS, FACC
}

\footnotetext{
From the Department of Cardiac Surgery, Mount Sinai Saint Luke's, Mount Sinai Beth Israel and Mount Sinai West (Roosvelt), New York, NY.

Disclosures: Authors have nothing to disclose with regard to commercial support.

Received for publication Sept 11, 2018; accepted for publication Sept 11, 2018; available ahead of print Nov 14 , 2018.

Address for reprints: John D. Puskas, MD, MSc, FACS, FACC, Department of Cardiac Surgery, Mount Sinai Saint Luke's, 1111 Amsterdam Avenue \#6A-147, Babcock Building 6th floor, 10025 New York, NY 10025 (E-mail: john.puskas@mountsinai.org).

J Thorac Cardiovasc Surg 2019;157:1837-8

$0022-5223 / \$ 36.00$

Copyright (C) 2018 Published by Elsevier Inc. on behalf of The American Association for Thoracic Surgery

https://doi.org/10.1016/j.jtcvs.2018.09.040
}

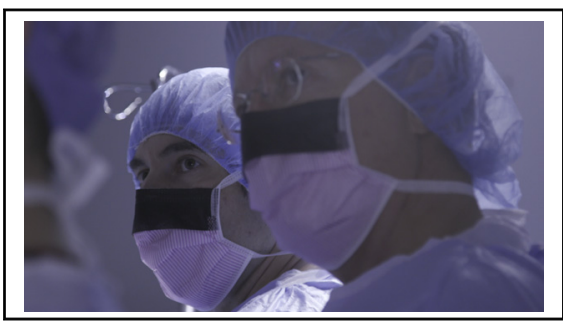

Dr Torregrossa (left) and Dr Puskas (right) during robot-assisted minimally invasive direct coronary artery bypass surgery.

Central Message

The future of coronary revascularization is TECAB multiarterial in hybrid approach to provide patients with the best possible longterm MACE-free survival while minimizing operative invasiveness.

See Article page 1829. heen performed by 64 teams in 22 countries. Following the initial enthusiasm with which cardiac transplantation was received, activity in this field declined rapidly as investigators became increasingly aware of the complex challenges involved. As a result, during 1974 only 27 heart transplants were performed worldwide; 15 of these procedures were performed at Stanford.",

The reality in 1975 was that half of the world's experience with heart transplantation was held by a single institution in which a specialist surgical team kept believing in, experimenting with, performing, and improving a procedure that would eventually change the lives of thousands of patients annually. Most surgeons at that time considered cardiac transplantation an extremely high-risk procedure with minimal benefit and unresolved ethical issues. Only during November 1983, 13 years after its discovery, was cyclosporine, a bioproduct derived from a Norwegian mushroom, approved by the US Food and Drug Administration for prevention of transplant graft rejection. ${ }^{2}$ Cyclosporine radically improved clinical outcomes of solid organ transplantation, influencing the life of millions of patients, and revived interest and progress in thoracic transplantation in particular.

In 1998, 30 years after the first heart transplant procedure was performed in the United States, Loulmet and colleagues ${ }^{3}$ performed the first total endoscopic coronary artery bypass (TECAB) procedure with the aid of robotassisted instruments. After initial enthusiasm, most of the centers worldwide that adopted this challenging new procedure abandoned it due to its many technical challenges in favor of well-established, easier alternative procedures.
Kitahara and colleagues ${ }^{4}$ report their experience at the University of Chicago with 57 patients treated with an advanced hybrid revascularization strategy using multiarterial off-pump TECAB in combination with percutaneous coronary intervention. These patients belong to a total of more than 300 consecutive TECAB operations performed by the group's senior surgeon Husam Balkhy over the past 4 years. The article reports $87.7 \%$ use of bilateral internal thoracic artery (BITA) grafts (to left-sided coronary targets) and 5 patients received triple-vessel bypass. The mean length of stay was 3 days and perioperative morbidity was significantly reduced, with no incidence of stroke, wound infection, postoperative myocardial infarction, or reexploration for bleeding. There was no in-hospital or 30-day mortality. The adoption of Flex-A anastomotic connectors (Cardica Inc, Redwood, Calif) made the TECAB off-pump strategy feasible with only 1 patient converted to on-pump beating heart and femoral cannulation due to intolerance of single-lung ventilation. The no-aortic touch off-pump technique associated with use of BITA can dramatically reduce the risk of perioperative stroke (described in an open chest setting by Albert and colleagues $^{5}$ ).

The patency of ITAs recorded in Kitahara and colleagues ${ }^{4}$ invites careful analysis. In a total of 110 ITAs evaluated via angiogram as part of the hybrid approach or regular follow-up, $5(4.5 \%)$ were occluded (Fitzgibbon 
grade O). The left ITA graft patency was $95.2 \%$, whereas right ITA patency was $95.7 \%$ at a mean follow-up period of 3 months. Unfortunately, Kitahara and colleagues ${ }^{4}$ do not include the data from transit time Doppler graft flow assessment recorded intraoperatively or other possible clues to better understand if there were any identifiable concerns at the time of surgery about the grafts that were ultimately occluded at follow-up. At midterm follow-up of 2 years, major adverse cardiac events (MACE) were recorded in 9 patients. Compared with patients who did not experience a major adverse cardiac event, these patients had higher rates of chronic obstructive pulmonary disease and a tendency toward less use of BITA grafting (Kitahara and colleagues ${ }^{4}$ present this information in their Table E1). These data support the importance of a second arterial conduit in the setting of a hybrid approach, emphasizing how expanding the use of BITA grafts, even in association with stents in a hybrid approach, should be an important goal of coronary revascularization strategies.

The exact role of the hybrid strategy in the armamentarium of interventional cardiologists and cardiac surgeons is currently under investigation by a National Institutes of Health-sponsored, multicenter, multinational clinical trial (ClinicalTrials.gov identifier: NCT01121263). A better understanding of which patients will benefit most from the hybrid approach will be clearer when that trial's results are reported 7 years from now. We recognize the importance of such a technique, particularly in a possible future health care environment in which minimizing length of stay and offering coronary artery bypass grafting within a closed chest may be essential to keep surgical coronary revascularization competitive with percutaneous alternatives. It is clear that the future of surgical coronary revascularization will be brightest if innovative coronary surgery specialists can provide patients with the best possible long-term major adverse cardiac event-free survival while minimizing operative invasiveness. In this robot-assisted approach, multiarterial BITA coronary artery bypass grafting is accomplished to the most important 2 coronary targets on the left side of the heart, preserving the fundamental benefit of the ITA-left anterior descending artery graft. Perioperative stroke risk is reduced to near zero with use of the off-pump anaortic technique with BITA grafting, risk of sternal wound infection is eliminated, and rapid recovery is expected.

Shumway and colleagues ${ }^{1}$ concluded their article on the state of the cardiac transplantation in 1975 with the following sentence: "Currently, it appears that 2 factors will determine whether cardiac transplantation will have a wider application for the treatment of end-stage cardiac disease: the first is donor organ supply ... the second is the inability to manipulate the host immune response." We conclude this editorial sharing the enthusiasm expressed by Kitahara and colleagues ${ }^{4}$ for TECAB multiarterial grafting and hybrid TECAB by defining those factors that appear to be necessary to broaden adoption of this technically demanding, advanced, robotic, multiarterial sternal-sparing approach:

1. Sophisticated procedure training enabled by the creation of a realistic simulator (similar to those adopted in aviation by pilots and in transcatheter aortic valve replacement by numerous valve manufacturers) must be established to allow for the development of critical new skills and team preparation for TECAB in preclinical settings.

2. Technologies to facilitate and simplify this procedure must be developed. With new robotic platforms coming to market, the ideal future would include a dedicated robotic platform customized for skeletonized BITA harvest and coronary anastomosis, which may involve artificial intelligence to semiautomate some functions and safety features, as well as supporting cardiac surgeons with more coronary surgery-specific robotic instruments.

3. A robust commitment from industry must be secured to sustain manufacture of the distal anastomotic connector market and to substantially miniaturize and improve that important facilitating technology to drive future innovation, simplification, and adoption of TECAB, both as a standalone procedure and as the primary portion of a hybrid multivessel coronary revascularization strategy.

We compliment Kitahara and colleagues ${ }^{4}$ for their important leadership role in this procedure, despite the absence of a TECAB Norwegian mushroom.

\section{References}

1. Rider AK, Copeland JG, Hunt SA, Mason J, Specter MJ, Winkle RA, et al. The status of cardiac transplantation, 1975. Circulation. 1975;52:531-9.

2. Kolata G. FDA speeds approval of cyclosporine. Science. 1983;221:1273.

3. Loulmet D, Carpentier A, d'Attellis N, Berrebi A, Cardon C, Ponzio O, et al, Endoscopic coronary artery bypass grafting with the aid of robotic assisted instruments. J Thorac Cardiovasc Surg. 1999;118:4-10.

4. Kitahara H, Hirai T, McCrorey M, Patel B, Nisivasco S, Nathan S, et al. Hybrid coronary revascularization: midterm outcomes of robotic multivessel bypass and percutaneous interventions. J Thorac Cardiovasc Surg. 2019;157:1829-36.e1.

5. Albert A, Ennker J, Hegazy Y, Ullrich S, Petrov G, Akhyari P, et al. Implementation of the aortic no-touch technique to reduce stroke after off-pump coronary surgery. J Thorac Cardiovasc Surg. 2018;156:544-54.e4. 